\title{
Pulmonary echinococcosis
}

\author{
R. Morar, C. Feldman
}

Pulmonary echinococcosis. R. Morar, C. Feldman. C) ERS Journals Ltd 2003.

ABSTRACT: Echinococcosis or hydatid disease is caused by larvae of the tapeworm Echinococcus. Four species are recognised and the vast majority of infestations in humans are caused by $\boldsymbol{E}$. granulosus. $\boldsymbol{E}$. granulosus causes cystic echinococcosis, which has a worldwide distribution. Humans are exposed less frequently to $E$. multilocularis, which causes alveolar echinococcosis. $E$. vogeli and $E$. oligarthrus are rare species and cause polycystic echinococcosis.

In cystic echinococcosis, humans are an accidental host and are usually infected by handling an infected dog. The liver and lungs are the most frequently involved organs. Pulmonary disease appears to be more common in younger individuals. Although most patients are asymptomatic, some may occasionally expectorate the contents of the cyst or develop symptoms related to compression of the surrounding structures. Other symptoms of hydatid disease can result from the release of antigenic material and secondary immunological reactions that develop from cyst rupture. The cysts are characteristically seen as solitary or multiple circumscribed or oval masses on imaging. Detection of antibody directed against specific echinococcal antigens is found in only approximately half of patients with pulmonary cysts. Surgical excision of the cyst is the treatment of choice whenever feasible.

Eur Respir J 2003; 21: 1069-1077.
Dept of Medicine, Division of Pulmonology, Johannesburg Hospital and University of the Witwatersrand, Johannesburg, South Africa.

Correspondence: C. Feldman

Dept of Medicine

University of the Witwatersrand

7 York Road

Parktown, 2193

Johannesburg

South Africa

Fax: 27114884675

E-mail: feldmanc@medicine.wits.ac.za

Keywords: Cystic echinococcosis

echinococcosis

hydatid disease

pulmonary

Received: November 262002

Accepted after revision: January 212003
Echinococcosis or hydatid disease is caused by larvae, which are the metacestode stage of the tapeworm Echinococcus. Four species are recognised and belong to the family Taeniidae. The vast majority of infestations in humans are caused by E. granulosus. E. granulosus causes cystic echinococcosis, the pastoral form, which has a worldwide distribution and is concentrated in sheep-raising areas. Humans are exposed less frequently to E. multilocularis, which causes alveolar echinococcosis, because E. multilocularis infestation usually occurs in colder areas and is associated with animals in wild ecosystems, especially foxes. E. vogeli and E. oligarthrus are rare species and cause polycystic echinococcosis.

Cystic echinococcosis caused by Echinococcus granulosus (hydatidosis or hydatid disease)

\section{Life cycle}

The different species of Echinococcus have different geographical distributions and involve different hosts (table 1). The hydatid tapeworm (E. granulosus) requires two hosts to complete its life cycle. Dogs (and other canines) are the definitive host and a variety of species of warm-blooded vertebrates (sheep, cattle, goats, horses, pigs, camels and humans) are the intermediate host. Humans are accidental hosts and do not play a role in the biological cycle. The adult worm inhabits the small intestine of the definitive host, is usually 2-7 $\mathrm{mm}$ long, is attached to the mucosa by a double row of hooklets contained in its scolex and has at least three proglottids, which contain numerous eggs. The eggs pass out in the faeces of the dog and stick to the animal's fur or to grass. These eggs can survive for at least a year in the outside world, during which time they are widely dispersed. Flies help to spread the eggs, as does the wind. The adult tapeworms do not make their hosts ill. Intermediate hosts ingest eggs when grazing on contaminated ground and the embryos are released after hatching in the small intestine. Embryos then enter the portal circulation through the intestinal wall and travel to visceral capillary beds, usually the liver or the lung, where they develop into cystic metacestodes. The parasite then grows to form a cyst filled with fluid. The interior of a cyst is filled with protoscolices, each of which has the ability to grow into an adult worm when ingested by a canine host. Cysts may contain hundreds or thousands of protoscolices and this tremendous reproductive potential poses a problem in the intermediate host (particularly in humans). Protoscolices can develop into either secondary cysts, known as daughter cysts, or a mature worm. Daughter cysts occur in the organs of the intermediate host, whereas mature worms are found in the definitive host if organs infected with protoscolices are ingested. Development into a mature worm within the intestine of a definitive host occurs over a period of

Previous articles in this series: No. 1: Tärnvik A, Berglund L. Tularaemia. Eur Respir J 2003; 21: 361-373. No. 2: Mabeza GF, Macfarlane J. Pulmonary actinomycosis. Eur Respir J 2003; 21: 545-551. No. 3: Marrie TJ. Coxiella burnetii pneumonia. Eur Respir J 2003; 21: 713-719. No. 4: Mohsen AH, McKendrick M. Varicella pneumonia in adults. Eur Respir J 2003; 21: 886-891. 
Table 1.-Epidemiological features and host characteristics of Echinococcus

\begin{tabular}{|c|c|c|c|c|}
\hline & $\begin{array}{l}\text { Geographical } \\
\text { distribution }\end{array}$ & $\begin{array}{l}\text { Frequency and severity } \\
\text { of human infection }\end{array}$ & Definitive host & Intermediate host \\
\hline E. granulosus & Worldwide & $\begin{array}{l}\text { Majority of human } \\
\text { infection caused by } \\
\text { this strain, also the } \\
\text { most pathogenic }\end{array}$ & Primarily dogs, other canines & $\begin{array}{l}\text { Sheep, cattle, horses, } \\
\text { pigs, camels }\end{array}$ \\
\hline E. multilocularis & $\begin{array}{l}\text { Northern Hemisphere } \\
\text { (Central Europe, Russia, } \\
\text { western China, northern } \\
\text { Japan, North America, } \\
\text { North Africa) }\end{array}$ & $\begin{array}{l}\text { Restricted animal } \\
\text { hosts limit human } \\
\text { infection but severe } \\
\text { infections can occur }\end{array}$ & $\begin{array}{l}\text { Primarily foxes, } \\
\text { wolves, dogs, coyotes, cats }\end{array}$ & $\begin{array}{l}\text { Rodents, deer, moose, } \\
\text { reindeer, bison }\end{array}$ \\
\hline E. vogeli & Central and South America & $\begin{array}{l}\text { Disease intermediate } \\
\text { in severity between } \\
\text { E. granulosus and } \\
\text { E. multilocularis }\end{array}$ & Wild canines (bush dogs) & Rodents, pacas \\
\hline E. oligarthrus & $\begin{array}{l}\text { Central and South } \\
\text { America }\end{array}$ & Only few reported cases & Wild felids (pumas, jaguars) & Rodents, rabbits \\
\hline
\end{tabular}

4-7 weeks and completes the life cycle. Since two mammalian species are required for completion of the life cycle, direct transmission of echinococcosis from human to human does not occur. The life cycle is completed when carnivores ingest the cysts in the viscera of intermediate hosts. Each larval tapeworm can then develop into an adult tapeworm, which eventually produces new eggs and thereby continues the cycle. Humans may serve as intermediate hosts, being infected by contact with infected dogs or by ingestion of eggs from contaminated food, water or soil. The eggs can also be inhaled, causing primary lung disease [1-4].

\section{Epidemiology}

Cystic echinococcosis is seen worldwide. Considerable public health problems are encountered in endemic areas, such as South and Central America, the Middle East, subSaharan Africa, Russia, China, Australia and New Zealand. Most cases in the USA and Central Europe occur in immigrants from endemic areas [3].

\section{Parasite biology}

The fully developed cysts are composed of three layers. The outer layer, or pericyst, is composed of inflamed fibrous tissue derived from the host; the exocyst is an acellular laminated membrane; and the innermost layer, or endocyst, is the germinative layer of the parasite and gives rise to brood capsules (secondary cysts), which bud internally [5]. Protoscolices are produced within the brood capsules and take approximately a year to develop after infection. An intact cyst, if large, may be filled with litres of fluid. The fluid, which is antigenic and may contain debris, contains hooklets and scolices and is referred to as hydatid sand. It has characteristic radiographic and sonographic features [6]. Daughter cysts may develop directly from the endocyst, resulting in multicystic structures (table 2).

\section{Immunity}

In humans, protection following primary infection is mediated by humoral and cellular immunity. Immune responses initially occur against the oncosphere that penetrates the small intestinal mucosa and subsequently against the metacestode.
Metacestodes have developed highly effective mechanisms for evading host defences. The membranes and host capsule contribute to protecting the parasite from immune destruction [7]. Parasite-derived anticomplement factor may dampen host immune response [1]. T-helper cell type 1 activation is crucial for protective immunity, whereas the T-helper cell type 2 response is associated with susceptibility to progressive disease [8].

\section{Organ involvement}

Following ingestion of E. granulosus eggs, the metacestode cyst can be found in virtually any organ (primary echinococcosis). Secondary echinococcosis results from the spread of the metacestodes from the primary sites. Of patients with cystic echinococcus, $85-90 \%$ show single organ involvement and $>70 \%$ harbour a solitary cyst. The liver is the most common site of cyst formation, followed by the lung in $10-30 \%$ of cases and other sites (usually the spleen, kidney,

Table 2.-Cyst characteristics of the various Echinococcus species

\begin{tabular}{|c|c|c|}
\hline & $\begin{array}{l}\text { Nature of larval } \\
\text { form in humans }\end{array}$ & Cyst components \\
\hline E. granulosus & $\begin{array}{l}\text { Cystic, } \\
\text { unilocular, } \\
\text { expansile }\end{array}$ & $\begin{array}{l}\text { Metacestode has } \\
\text { endocyst (internal } \\
\text { germinal layer), } \\
\text { exocyst (parasite- } \\
\text { derived acellular } \\
\text { laminated layer) } \\
\text { and pericyst (host- } \\
\text { derived adventitial } \\
\text { layer) }\end{array}$ \\
\hline E. multilocularis & $\begin{array}{l}\text { Multilocular, } \\
\text { infiltrative }\end{array}$ & $\begin{array}{l}\text { Very thin laminated } \\
\text { layer only and no } \\
\text { pericyst, which } \\
\text { enables tissue invasion }\end{array}$ \\
\hline $\begin{array}{l}\text { E. vogeli } \\
\text { E. oligarthrus }\end{array}$ & $\begin{array}{l}\text { Polycystic, } \\
\text { expansile }\end{array}$ & $\begin{array}{l}\text { Large cysts with } \\
\text { multiple vesicles are } \\
\text { separated by septa } \\
\text { lined with germinal } \\
\text { epithelium; externally, } \\
\text { cyst is surrounded } \\
\text { by fibrous tissue }\end{array}$ \\
\hline
\end{tabular}


orbit, heart, brain and bone) in $\sim 10 \%$ of cases [1-4]. In children, the lungs may be the commonest site of cyst formation [9]. Of patients with lung cysts, $\sim 20-40 \%$ also have liver cysts $[10,11]$. Pulmonary hydatid disease affects the right lung in $\sim 60 \%$ of cases, $30 \%$ exhibit multiple pulmonary cysts, $20 \%$ bilateral cysts and $60 \%$ are located in the lower lobes [9]. Pulmonary echinococcosis can follow intrathoracic rupture of a cyst of the liver [12], but most patients with pulmonary hydatid disease do not show liver involvement [13]. Within the chest, echinococcosis can primarily involve the pleural cavity [14], mediastinum [15] and chest wall [16].

\section{Clinical features}

Although larvae can enter the lungs through the lymphatic system or bronchial system, it is thought that cysts settling down in the lungs are usually larvae that have passed through the hepatic sinusoids $[1,3]$. Pulmonary cysts typically increase in diameter at a rate of $1-5 \mathrm{~cm} \cdot \mathrm{yr}^{-1}$ [17].

The initial phase of primary infection is asymptomatic and may remain so for many years. Hydatid disease is seen in subjects of any age and sex, although it is more common in those aged 20-40 yrs [11, 18]. Most intact lung cysts are discovered incidentally on chest radiographs. Occasionally, an unruptured cyst results in cough, haemoptysis or chest pain [13]. Subsequent clinical features of E. granulosus infection depend upon the cyst site and size. Small cysts may remain asymptomatic indefinitely, but cysts may enlarge to $>20 \mathrm{~cm}$ in diameter and cause symptoms by compressing adjacent structures. Mediastinal cysts may erode into adjacent structures causing bone pain, haemorrhage or airflow limitation. Symptomatic hydatid disease of the lung, however, more often follows rupture of the cyst. The cyst may rupture spontaneously or as a result of trauma or secondary infection. In a contained rupture, only the endocyst is torn and the contents of the cyst are contained by the pericyst. In a communicating rupture, the contents of the cyst escape into the tracheobronchial tree through bronchioles that have been incorporated into the pericyst. Direct rupture into the pleura follows tearing of both the endocyst and the pericyst, with discharge of the contents of the cyst directly into the pleural cavity [19]. Rupture may be associated with the sudden onset of cough and fever. If the contents of the cyst are expelled into the airway, expectoration of a clear salty or peppery tasting fluid containing fragments of hydatid membrane and scolices may occur.

Symptoms of hydatid disease can result from the release of antigenic material and secondary immunological reactions that develop following cyst rupture. Fever and acute hypersensitivity reactions ranging from urticaria and wheezing to life-threatening anaphylaxis may be the principal manifestations. Although allergic episodes may develop after cyst rupture, fatal anaphylaxis is uncommon $[20,21]$.

Other potential clinical effects of hydatid infection include immune complex-mediated disease, glomerulonephritis leading to nephrotic syndrome, and secondary amyloidosis [22, 23]. Ruptured cysts may become infected with bacteria or saprophytic or invasive fungi, which are serious complications $[24,25]$.

Hydatid disease is a rare cause of recurrent acute pulmonary embolism. This complication may develop after invasion of the cardiovascular system or direct invasion of the inferior vena cava [26].

Calcification, which usually requires 5-10 yrs for development, occurs quite commonly with hepatic cysts but rarely with pulmonary cysts. Bone cysts also do not undergo calcification. Total calcification of the cyst wall suggests that the cyst may be nonviable [3, 27].
Involvement of the diaphragm and thoracic cavity occurs in $\sim 1-16 \%$ of cases of hepatic hydatid disease [10]. Transdiaphragmatic migration of hydatid disease from the posterior segments of the right hepatic lobe has been reported to be a common complication and is probably related to their proximity to the diaphragm.

\section{Diagnosis}

In the majority of cases, a combination of imaging and serological methods usually yields the diagnosis of cystic echinococcosis. A patient who has lung cysts should be investigated for associated liver cysts.

Imaging. The most valuable diagnostic method in pulmonary hydatid disease is the plain chest radiograph [11, 27-31]. Typical chest radiographic appearances of uncomplicated pulmonary hydatid disease are one or more homogeneous round or oval masses with smooth borders surrounded by normal lung tissue (fig. 1) [31]. Pulmonary cysts may range between 1 and $20 \mathrm{~cm}$ in diameter [32]. Large cysts can shift the mediastinum, induce a pleural reaction or cause atelectasis of adjacent parenchyma. Impingement on relatively rigid anatomical structures can lead to irregularity, indentation or lobulation of the cyst. The fluid contents of the cyst may be identified by the finding of a change in the shape of the cyst on serial radiographs obtained during inspiration and expiration or with the patient erect and then supine. Calcification of pulmonary cysts is rare. On chest radiography, calcification of hepatic cysts may be evident [31].

Cyst growth produces erosions in the bronchioles that are included in the pericyst, and, as a result, air is introduced between the pericyst and exocyst, producing the crescent or meniscus sign [31, 32]. Some consider this to be a sign of impending rupture [31]. Air penetrating the interior of the cyst may outline the inner surface of the exocyst, producing parallel arches of air that are referred to as Cumbo's sign with an "onion peel" appearance [32]. Although these radiographic features can be diagnostic of pulmonary hydatid disease, they are uncommon [31]. If the ruptured cyst communicates with the tracheobronchial tree, evacuation of the contents of the cyst results in an air/fluid level. After partial expectoration of the cyst fluid and scolices, the cyst empties and the collapsed membranes can be seen inside the cyst (serpent sign). When it has completely collapsed, the crumpled endocyst floats freely in the cyst fluid (water-lily sign or Camelotte sign). When the fluid is completely evacuated by expectoration, the remaining solid components fall to the dependent part of the cavity giving the "mass within a cavity" or Monod's sign. Like the crescent sign, the water-lily sign, which is pathognomonic of a collapsed endocyst, is seen in the minority of cases. For pulmonary ecchinococcosis, ultrasonography is unhelpful in most cases unless the cysts are close to the pleural surface (fig. 2) [31, 32].

Computerised tomography (CT) scan with contrast may demonstrate a thin enhancing rim if the cyst is intact (fig. 3). The contents of closed simple cysts are homogeneous, with a density close to that of water [33]. Unruptured cysts are often indistinguishable from a variety of other pulmonary lesions, but the diagnosis may be established by finding daughter cysts attached to the endocyst or lying free within the main cyst or rupture of the main cyst. CT scanning can elucidate the cystic nature of the lung mass and provide accurate localisation for planning of surgical treatment of complicated cysts. The inverse crescent sign results from air dissection-induced separation of the membranes from the posterior aspect of the cyst without any anterior extension and bleb of air dissecting into the wall of the cyst, giving it the shape of a ring 

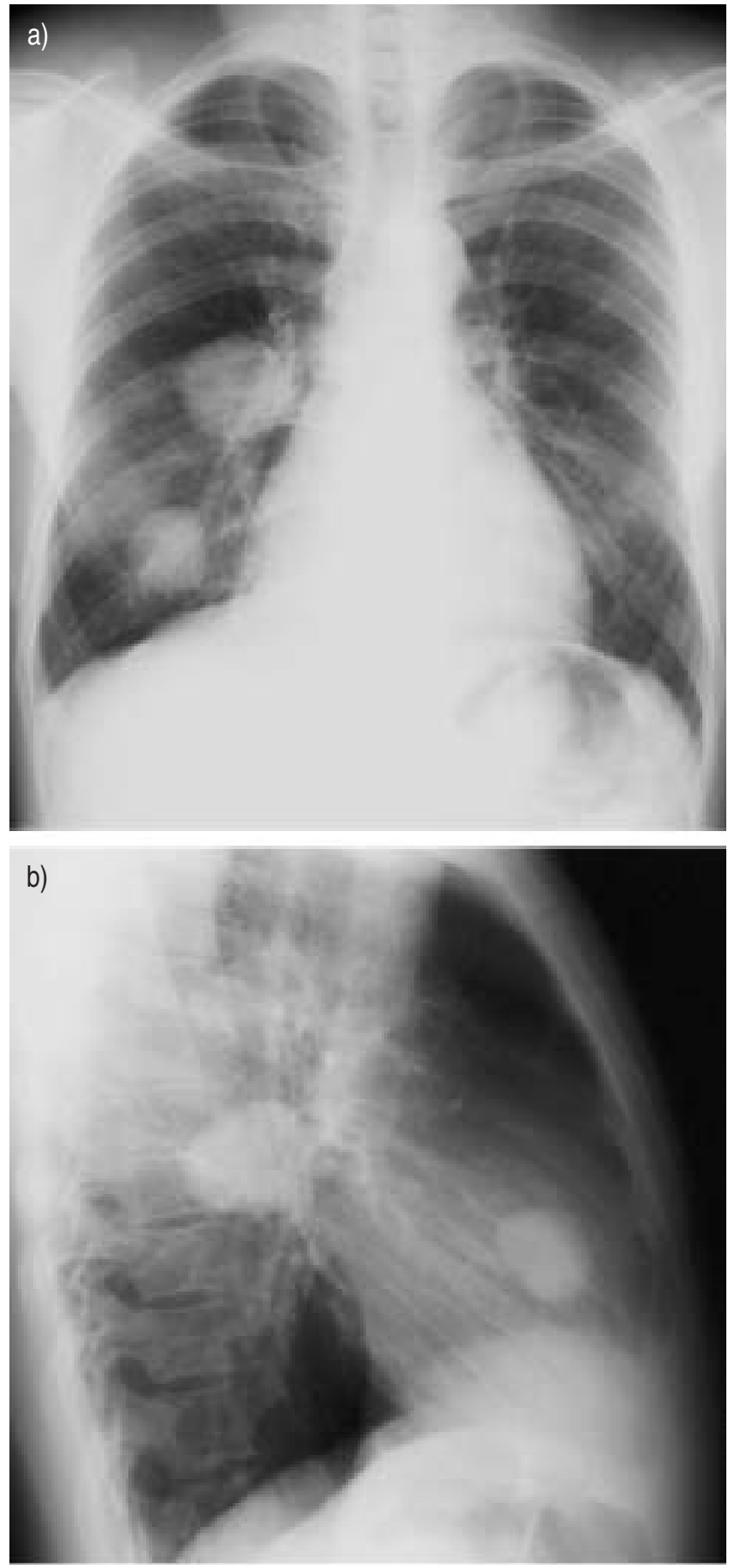

Fig. 1.-a) Posteroanterior and b) lateral chest radiography showing well-defined rounded opacities in the right lung of a patient with unruptured cystic echinococcosis.

termed the signet ring sign. In addition, an increase in the CT density of the lung mass and/or a thick wall should not negate a diagnosis of hydatid disease [34].

The magnetic resonance signal characteristics of a hydatid cyst may differ depending on the developmental phase, i.e. whether it is uni- or multilocular and whether the cyst is viable, infected or dead. Information regarding reactive changes in the host tissue, capsule and signal intensity of parent and daughter cysts is also obtained. On magnetic resonance imaging (MRI), cysts show low signal intensity on T1-weighted images and high signal intensity on T2-weighted images [35].
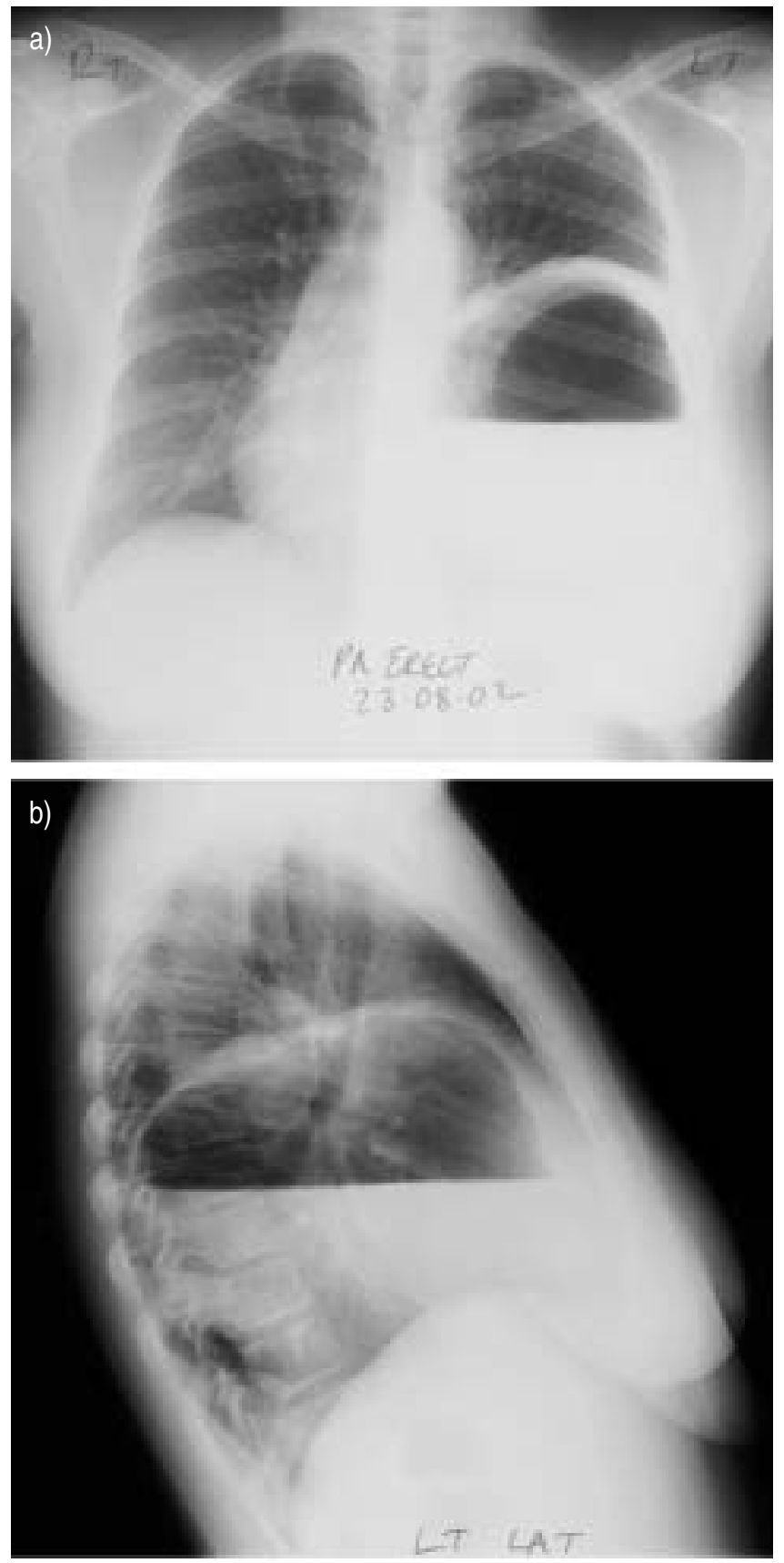

Fig. 2. - a) Posteroanterior and b) lateral chest radiography showing a hydropneumothorax in a patient with ruptured cystic hydatidosis with discharge of contents into the pleural space.

Immunoscintigraphy utilises radiolabelled antibodies raised to parasite antigens. Although not yet widely available clinically, this may be a specific imaging modality in the future [36].

\section{Laboratory and special investigations}

Laboratory. In pulmonary cystic echinococcosis, routine laboratory tests do not show specific results. Less than $15 \%$ of cases exhibit eosinophilia, which generally occurs only if there is leakage of antigenic material $[11,37]$.

Serology. Immunodiagnostic testing for serum antibodies or circulating antigen provides supportive evidence of pulmonary 


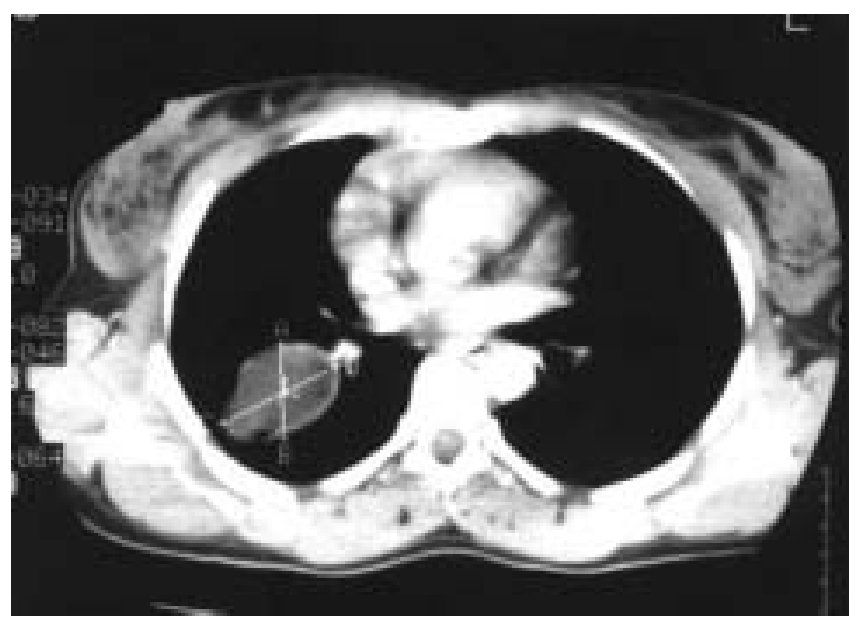

Fig. 3.-Computerised tomography scan of the lung showing a cystic mass measuring $3 \times 5 \mathrm{~cm}$ in the right lower lobe of a patient with cystic hydatidosis.

echinococcosis. An enzyme-linked immunosorbent assay or indirect haemagglutination test is commonly used as an initial screen, and is positive in only $\sim 50 \%$ of patients with pulmonary hydatidosis and $>90 \%$ of patients with hepatic cysts [38]. Testing for specific antibodies, such as specific immunoglobulin G1 or G4 rather than total immunoglobulin G, may improve the specificity of a test $[39,40]$. The specificity of these tests increases considerably when utilising antigen 5 (arc 5 test), immunoblotting or gel diffusion assay for specific hydatid antigen. Antigen 5 is a major parasite antigen found on the inner aspect of the germinal layer, brood capsule and protoscolices. Antigen B, located on the protoscolices, and particularly its smallest subunit of $8 \mathrm{kDa}$, offers greater specificity than does detection of antigen 5 [41, 42].

Serological testing produces both many false-positive and many false-negative results. False-positive reactions are more likely in the presence of other helminthic infections (particularly neurocysticercosis), cancer and immune disorders. Falsenegative results occur with varying frequency depending upon the site of the lesion and cyst integrity and viability. A negative serological test generally does not rule out echinococcosis [43]. Serology is less likely to be positive if the cysts at any site are intact, calcified or nonviable, and children and pregnant subjects more frequently exhibit negative serology $[3,27,43]$.

Currently, polymerase chain reaction (PCR) techniques are only being used for research purposes, but they may have a role to play in diagnosis and species determination in the future. Deoxyribonucleic acid probes using Southern hybridisation tests are also being developed [44].

Percutaneous aspiration. Inadvertent percutaneous aspiration can confirm the diagnosis by demonstrating the presence of protoscolices, hooklets or hydatid membranes. Active cysts exhibit clear watery fluid containing scolices and show elevated pressure, whereas inactive cysts exhibit cloudy fluid without detectable scolices and do not show elevated pressure [45]. Owing to the possibility of cyst rupture, anaphylaxis and dissemination of cyst contents, percutaneous aspiration of lung cysts has been considered too risky for routine diagnostic use, although this procedure is now commonly used for the diagnosis and treatment of hepatic echinococcal cysts [4]. Several reports of this approach have shown it to be successful in patients with pulmonary hydatid disease [46, 47].

Protoscolices or degenerated hooklets can sometimes be demonstrated in sputum, bronchial washings or pleural fluid.

\section{Management}

Surgical treatment. For patients who are able to undergo surgery, it is considered the treatment of choice since the parasite can be completely removed and the patient cured. The surgical options for lung cysts include lobectomy, wedge resection, pericystectomy, intact endocystectomy and capitonnage [48]. During surgery it is important to rigorously minimise spillage of cyst contents in order to prevent intraoperative dissemination and eventual recurrence. This may be accomplished by the delivery of intact cyst or by cystic fluid aspiration with or without the use of a scolicidal solution and preoperative therapy with albendazole [49].

Puncture, aspiration or injection of a helminthicide and reaspiration has been advocated for hepatic cysts. However, for pulmonary cysts, this technique shows more complications and is rarely indicated [50, 51].

Scolicidal agents such as hypertonic saline, cetrimide, povidone-iodine, formalin, ethanol or hydrogen peroxide may be used. If a protoscolicidal agent is used, it must remain in contact with the cyst for $\geqslant 15 \mathrm{~min}$. Most surgeons use $1 \%$ formaldehyde or hypertonic saline solution for deactivation of cysts and protection of the operative field [52].

Bilateral hydatid disease of the lungs may be managed by one- or two-stage surgery via either bilateral thoracotomy, sternotomy or video-assisted thoracic surgery. Some prefer two-stage thoracotomy, operating on the side with the larger ruptured and infected cyst first. However, median sternotomy is a better alternative for the treatment of bilateral hydatid disease of the lung. This method is more economical, causes less pain and is better tolerated than two thoracotomic procedures [38, 49, 53-55].

Abdominal liver cysts may be treated during the same operation or separately. The lung is generally treated first [55]. Surgery is indicated in most cases of pulmonary cystic echinococcosis as operative mortality is low (1-2\%), morbidity rates are acceptable and the recurrence rate is low $(1-3 \%)$ $[11,14,37,48,56,57]$.

Medical treatment. Medical therapy with benzimidazoles is valuable in disseminated disease, including secondary lung or pleural hydatidosis, poor surgical risk patients and when there is intraoperative spillage of hydatid fluid (table 3) [49].

Adjunctive chemotherapy before and after surgery appears to reduce the risk of recurrence by inactivating protoscolices and reduces the tension of the cysts for easier cyst removal $[58,59]$. If spillage of the cyst contents occurs, either spontaneously or following iatrogenic manipulation, it is recommended that either mebendazole or albendazole be given to reduce the risk of secondary hydatidosis. However, the optimal duration of chemotherapy before and after surgical procedures is not known. Therapy generally should begin $\geqslant 4$ days prior to surgery and be continued for $1-3$ months $[46,49,60]$.

The usual dose of mebendazole is $40-50 \mathrm{mg} \cdot \mathrm{kg}$ body weight $^{-1} \cdot$ day $^{-1}$, given in three divided doses after meals (maximum daily dose $6 \mathrm{~g}$ ). Therapy is usually indicated for $\geqslant 3-6$ months. Albendazole is given at a dosage of 10 $15 \mathrm{mg} \cdot \mathrm{kg}$ body weight ${ }^{-1} \cdot$ day $^{-1}$ in two divided doses and the usual dose is $800 \mathrm{mg}$ daily. Therapy is most often indicated for a minimum of 3-6 months. Albendazole is preferred because it has better bioavailability [61].

Both drugs are also contraindicated in pregnancy (especially during the first trimester) because of possible teratogenicity. Medical treatment alone has been suggested by some to be sufficient for small pulmonary hydatid cysts [62, 63]. A newer benzimidazole compound, oxfendazole, has been studied in a mouse model and preliminary results suggest it may be a more effective compound [64]. 
Table 3. - Drugs used in the treatment of echinococcosis

\begin{tabular}{|c|c|c|c|}
\hline & Oral dosage & Duration & Maximum dose \\
\hline Mebendazole & $\begin{array}{l}40-50 \mathrm{mg} \cdot \mathrm{kg} \text { body weight } \\
\text { three times daily }\end{array}$ & 3-6 months for E. granulosus & $6 \mathrm{~g} \cdot \mathrm{day}^{-1}$ \\
\hline Albendazole ${ }^{\#}$ & $\begin{array}{l}10-15 \mathrm{mg} \cdot \mathrm{kg} \text { body weight }{ }^{-1} \cdot \mathrm{day}^{-1} \\
\text { twice daily }\end{array}$ & $\begin{array}{l}\text { 3-6 months for } E \text {. granulosus and } \\
\text { prolonged or lifelong for } E \text {. multilocularis }\end{array}$ & Usually $800 \mathrm{mg} \cdot \mathrm{day}^{-1}$ \\
\hline Praziquantel $^{\top}$ & $\begin{array}{l}40 \mathrm{mg} \cdot \mathrm{kg} \text { body weight } \\
\text { once weekly }\end{array}$ & Uncertain & NA \\
\hline
\end{tabular}

E.: Echinococcus; NA: not available. ${ }^{\#}$ : preferred because it exhibits better bioavailability than mebendazole; ${ }^{\top}$ : can combine with albendazole.

Praziquantel, an isoquinolone, has also been used for therapy. It has been shown to have effective protoscolicidal activity and may be more effective than albendazole in vitro. Praziquantel $\left(40 \mathrm{mg} \cdot \mathrm{kg}\right.$ body weight ${ }^{-1}$ orally once a week) has been used alone and in combination with albendazole. A few reports suggest that the combination of albendazole and praziquantel as medical therapy or as postspillage prophylaxis is more effective than either therapy alone $[38,65,66]$. The efficacy of praziquantel is variable and its role in primary chemotherapy is not clearly defined.

\section{Monitoring response to therapy}

Evaluating the success of therapy is difficult and usually requires regular follow-up and imaging. The use of serological titres to monitor therapy has also been assessed [67]. Serological tests showed an increase in titre in the majority of patients for the first 3 months after surgery, probably a result of antigen liberation during cyst manipulation. Serological tests showed decreasing antibody titres from 3 months after surgery in patients without relapse. Patients who relapse show either persistently high (early relapse) or an initial decrease and subsequent increase (late relapse) in antibody titres [67]. No serological test has consistently proved reliable in monitoring patients on chemotherapy for hydatid disease. There are no formal recommendations on how patients are best monitored whether by imaging or serology, and this needs to be individualised.

\section{Prevention}

Prevention of cystic echinococcosis can often be achieved by avoiding close contact with dogs. Careful washing of fresh produce can also reduce infection. Prohibition of homeslaughter of sheep and proper offal disposal prevents dogs from consuming infected viscera, thus disrupting the life cycle of the parasite. Elimination of stray dogs and surveillance techniques, involving either diagnostic purging of dogs or coproantigen tests, have helped to reduce infections in some endemic areas [68]. Vaccination is also a prospect for prevention of echinococcosis, since protective immunity develops in intermediate hosts [68-70].

\section{Alveolar echinococcosis caused by Echinococcus multilocularis (alveolar hydatid disease)}

\section{Life cycle}

The life cycle involves wild canine, usually foxes and wolves, as definitive hosts and rodents, deer, moose, reindeer and bison as intermediate hosts. Domestic dogs or cats may also become infected and can transmit the infection to humans directly or contaminate food with parasite eggs. The exact incidence of human infection with E. multilocularis is not known but is significantly less common than disease due to E. granulosus [1-4].

\section{Epidemiology}

E. multilocularis occurs almost exclusively in the Northern Hemisphere, particularly in parts of Central Europe, Russia, western China, northern Japan, North America (in subarctic regions of Alaska and Canada) and North Africa [1-3]. E. multilocularis causes alveolar echinococcosis, which accounts for $<5 \%$ of all cases of hydatid liver disease and, less frequently, lung disease $[3,38]$.

\section{Parasite biology}

The cysts of E. multilocularis are typically slow growing, with an estimated incubation period of 5-15 yrs. Exogenous budding and proliferation of the cyst, which lacks a limiting membrane of parasite or host origin, causes infiltration into adjacent tissues and results in pressure necrosis of surrounding host tissue. The lesions are composed of numerous irregular cysts of various sizes (a few millimetres to a few centimetres), with no sharp demarcation from surrounding organ tissue [1-3].

Microscopically, the cysts are composed of a thin laminated layer with minimal or no germinal layer. Brood capsules and protoscolices form in $<10 \%$ of these cysts, which, instead, reproduce by asexual lateral budding. Spontaneous death of metacestodes and degeneration of lesions may occur [71].

\section{Immunity}

Both humoral and cellular immunity are activated by this parasite. The role of antibodies in controlling metacestode proliferation has not been proved. T-lymphocyte responses may be more important in controlling infection [3, 72]. Certain human leukocyte antigens have been implicated in protection or susceptibility to infection [73].

\section{Clinical features and organ involvement}

E. multilocularis can cause a severe and often fatal infection in humans. The mean age at presentation is 55 yrs [3]. The metacestode tissue behaves similarly to a malignant tumour, which invades and destroys tissue, extends beyond organ borders into adjacent structures, and metastasises to distant sites, such as the lung, brain and other organs. The liver is the primary site of cyst development in almost all patients. If left untreated, $>90 \%$ of patients will die within 10 yrs from onset of symptoms, and virtually $100 \%$ by 15 yrs $[3,74,75]$.

Lung manifestations always occur after hepatic involvement. Transdiaphragmatic contiguous migration of hepatic 
lesions is common and intrathoracic rupture of hepatic cysts into the bronchial tree, pleural cavity or mediastinum may occur. Hepatic lesions may invade the inferior vena cava and hepatic veins with metastases to the right atrium with parasitic pulmonary emboli which is rapidly fatal [3].

\section{Diagnosis}

The combination of imaging and serology usually enables diagnosis of both cystic and alveolar echinococcosis, although the latter is more sensitive and specific for $E$. multilocularis infection.

\section{Imaging}

Liver lesions on ultrasonographic or CT scan usually have an irregular contour without a well-defined wall, central necrosis, and irregular intralesional and wall calcifications. They may be difficult to distinguish from a tumour, but the patient's overall condition is generally better than would be expected with a malignancy. Obstruction of the inferior vena cava or the portal venous system may be evident and may be more easily appreciated on MRI scan. Lung, brain and bone lesions may also be detected in a similar manner [76].

\section{Serology}

Specific E. multilocularis antigens, such as Em2 and Em18, are often used in the serodiagnosis of alveolar echinococcosis. These antigens can discriminate between E. granulosus and E. multilocularis in $95-97 \%$ of cases [77-80].

Open biopsy may be required in seronegative patients. In the future, PCR may allow earlier detection of infection [81-83].

Fluorodeoxyglucose positron emission tomography may allow distinction between metabolically active lesions and nonenhancing metabolically inactive lesions [84]. This is a useful tool for assessing response to therapy and detecting relapses; however, it is expensive and not widely available.

\section{Treatment}

The treatment for alveolar echinococcosis generally is less effective than that for the cystic form as there are delays in diagnosis and the invasiveness of the metacestode renders many patients inoperable. Screening high-risk populations to detect disease may improve the prognosis earlier.

Surgical. The treatment in operable cases is radical surgical resection of the entire lesion, followed by chemotherapy. Surgery often involves extensive resection of host tissue with complete excision of larval tissue. Even following extensive surgery, a minimum of 2 yrs of chemotherapy is recommended and monitoring for possible recurrence for a minimum of $10 \mathrm{yrs}$ is advised [85].

Medical. For patients with unresectable or incompletely resected lesions, long-term chemotherapy is recommended. Albendazole $\left(10-15 \mathrm{mg} \cdot \mathrm{kg}\right.$ body weight ${ }^{-1} \cdot \mathrm{day}^{-1}$ orally in two divided doses, usually $800 \mathrm{mg}$ daily) is used. Medical therapy can improve the quality and length of survival, even when not curative [86, 87]. The optimal duration of therapy and whether or not prolonged or lifelong therapy is indicated remain unclear.
Praziquantel has also been used for alveolar echinococcosis but data from animal models are disappointing.

Liver transplantation is an option for therapy in patients with unresectable liver lesions. However, residual parasite tissue may be prone to more rapid growth because of immunosuppression and post-transplant adjuvant chemotherapy with a benzimidazole is advised [88].

\section{Echinococcus vogeli}

E. vogeli causes polycystic hydatid disease. Dogs and other canine serve as the definitive hosts, and pacas and other rodents are the principal intermediate hosts. E. vogeli occurs in central and northern South America. The clinical disease is intermediate in severity between cystic and alveolar infections [89]. The liver is involved in the majority of cases and the lungs are involved in $\sim 15 \%$ [1-3]. Serological tests are unable to differentiate $E$. vogeli from other echinococcal species. Treatment for E. vogeli has not been well studied.

\section{Echinococcus oligarthrus}

E. oligarthrus also causes polycystic echinococcosis. The parasite uses wild felids, such as pumas and jaguars, as definitive hosts; intermediate hosts include rodents and rabbits [1-3]. Only three cases of E. oligarthrus infection have been documented in South America [89-91]. Metacestodes in animals tend to localise in muscles or other extrahepatic sites, such as the eye and the heart, and the liver is involved less frequently. Little is known about optimal treatment.

\section{Conclusion}

Surgery remains the primary choice of treatment in cystic pulmonary echinococcosis. In inoperable alveolar echinococcosis, long-term chemotherapy is advocated. The ultimate aim is to have proper control measures and prevent these cestode infestations. A better understanding of hydatid immunoregulation may pave the way to rational immunotherapy and future vaccine development.

\section{References}

1. Schantz P. Echinococcosis. In: Guerrant R, Walker DH, Weller PF, eds. Tropical Infectious Diseases: Principles, Pathogens and Practice. Philadelphia, WB Saunders, 1999; pp. 1005-1025.

2. King CH. Cestodes (tapeworms). In: Mandell GL, Bennett JE, Dolin R, eds. Principles and Practice of Infectious Diseases. New York, Churchill Livingstone, 1995; pp. 2544 2553.

3. Ammann RW, Eckert J. Cestodes. Echinococcus. Gastroenterol Clin North Am 1996; 25: 655-689.

4. Kammerer WS, Schantz PM. Echinococcal disease. Infect Dis Clin North Am 1993; 7: 605-618.

5. Noble ER, Noble GA, Schad GA, MacInnes AJ, eds. Parasitology: the Biology of Animal Parasites. Philadelphia, Lea \& Febiger, 1989; pp. 211-249.

6. Suwan Z. Sonographic findings in hydatid disease of the liver: comparison with other imaging methods. Ann Trop Med Parasitol 1995; 89: 261-269.

7. Taratuto AL, Venturiello SM. Echinococcosis. Brain Pathol 1997; 7: 673-679.

8. Rigano R, Profumo E, Ioppolo S, Notargiacomo S, Teggi A, 
Siracusano A. Immunological markers indicating the effectiveness of pharmacological treatment in human hydatid disease. Clin Exp Immunol 1995; 102: 281-285.

9. Thumler J, Munoz A. Pulmonary and hepatic echinococcosis in children. Pediatr Radiol 1978; 7: 164-171.

10. Gomez R, Moreno E, Loinaz C, et al. Diaphragmatic or transdiaphragmatic thoracic involvement in hepatic hydatid disease: surgical trends and classification. World J Surg 1995; 19: 714-719.

11. Dogan R, Yuksel M, Cetin G, et al. Surgical treatment of hydatid cysts of the lung: report on 1055 patients. Thorax 1989; 44: 192-199.

12. Xanthakis DS, Katsaras E, Efthimiadis M, Papadakis G, Varouchakis G, Aligizakis C. Hydatid cyst of the liver with intrathoracic rupture. Thorax 1981; 36: 497-501.

13. Jerray M, Benzarti M, Garrouche A, Klabi N, Hayouni A. Hydatid disease of the lungs: study of 386 cases. Am Rev Respir Dis 1992; 146: 185-189.

14. Aribas OK, Kanat F, Gormus N, Turk E. Pleural complications of hydatid disease. J Thorac Cardiovasc Surg 2002; 123 : 492-497.

15. Rakower J, Milwidsky H. Primary mediastinal echinococcosis. Am J Med 1960; 29: 73-83.

16. Ozdemir N, Akal M, Kutlay H, Yavuzer S. Chest wall echinococcosis. Chest 1994; 105: 1277-1279.

17. Case Records of the Massachusetts General Hospital. Weekly clinicopathological exercises. Case 45-1987. A 16year-old girl with hepatic and pulmonary masses after a sojourn in Bolivia. N Engl J Med 1987; 317: 1209-1218.

18. Zapatero J, Madrigal L, Lago J, Baschwitz B, Perez E, Candelas J. Surgical treatment of thoracic hydatidosis. A review of 100 cases. Eur J Cardiothorac Surg 1989; 3: 436440.

19. Lewall DB, McCorkell SJ. Rupture of echinococcal cysts: diagnosis, classification, and clinical implications. AJR Am J Roentgenol 1986; 146: 391-394.

20. Giulekas D, Papacosta D, Papaconstantinou C, Barbarousis D, Angel J. Recurrent anaphylactic shock as a manifestation of echinococcosis: report of a case. Scand $J$ Thorac Cardiovasc Surg 1986; 20: 175-177.

21. Solak H, Ceran S, Ozpinar C, et al. Lung hydatid cyst rupture and its surgery. Indian J Med Sci 1994; 48: 155-157.

22. Gelman R, Brook G, Green J, Ben-Itzhak O, Nakhoul F. Minimal change glomerulonephritis associated with hydatid disease. Clin Nephrol 2000; 53: 152-155.

23. Ali-Khan Z, Rausch RL. Demonstration of amyloid and immune complex deposits in renal and hepatic parenchyma of Alaskan alveolar hydatid disease patients. Ann Trop Med Parasitol 1987; 81: 381-392.

24. Kini U. Invasive mycosis of a pulmonary hydatid cyst in a non-immunocompromised host. J Trop Med Hyg 1995; 98: $404-406$.

25. Date A, Zachariah N. Saprophytic mycosis with pulmonary echinococcosis. J Trop Med Hyg 1995; 98: 416-418.

26. Lioulias A, Kotoulas C, Kokotsakis J, Konstantinou M. Acute pulmonary embolism due to multiple hydatid cysts. Eur J Cardiothorac Surg 2001; 20: 197-199.

27. Bhatia G. Echinococcus. Semin Respir Infect 1997; 12: 171186.

28. Burgos R, Varela A, Castedo E, et al. Pulmonary hydatidosis: surgical treatment and follow-up of 240 cases. Eur J Cardiothorac Surg 1999; 16: 628-634.

29. Yalcinkaya I, Er M, Ozbay B, Ugras S. Surgical treatment of hydatid cyst of the lung: review of 30 cases. Eur Respir $J$ 1999; 13: 441-444.

30. Altintas N. Cystic and alveolar echinococcosis in Turkey. Ann Trop Med Parasitol 1998; 92: 637-642.

31. Beggs I. The radiology of hydatid disease. AJR Am J Roentgenol 1985; 145: 639-648.

32. Balikian JP, Mudarris FF. Hydatid disease of the lungs: a roentgenologic study of 50 cases. AJR Am J Roentgenol 1974; 122: 692-707.
33. Saksouk FA, Fahl MH, Rizk GK. Computed tomography of pulmonary hydatid disease. J Comput Assist Tomogr 1986; 10: 226-232.

34. Koul PA, Koul AN, Wahid A, Mir FA. CT in pulmonary hydatid disease: unusual appearances. Chest 2000; 118: 16451647.

35. Singh S, Gibikote SV. Magnetic resonance imaging signal characteristics in hydatid cysts. Australas Radiol 2001; 45: 128-133.

36. Dhar P, Chaudhary A, Desai R, Agarwal A, Sachdev A. Current trends in the diagnosis and management of cystic hydatid disease of the liver. J Commun Dis 1996; 28: 221-230.

37. Aytac A, Yurdakul Y, Ikizler C, Olga R, Saylam A. Pulmonary hydatid disease: report of 100 patients. Ann Thorac Surg 1977; 23: 145-151.

38. Gottstein B, Reichen J. Hydatid lung disease (echinococcosis/ hydatidosis). Clin Chest Med 2002; 23: 397-408.

39. Ioppolo S, Notargiacomo S, Profumo E, et al. Immunological responses to antigen B from Echinococcus granulosus cyst fluid in hydatid patients. Parasite Immunol 1996; 18: 571-578.

40. Ramzy RM, Helmy H, El Zayyat EA, et al. An enzymelinked immunosorbent assay for detection of IgG1 antibodies specific to human cystic echinococcosis in Egypt. Trop Med Int Health 1999; 4: 616-620.

41. Liance M, Janin V, Bresson-Hadni S, Vuitton DA, Houin R, Piarroux R. Immunodiagnosis of Echinococcus infections: confirmatory testing and species differentiation by a new commercial Western Blot. J Clin Microbiol 2000; 38: 37183721.

42. Poretti D, Felleisen E, Grimm F, et al. Differential immunodiagnosis between cystic hydatid disease and other cross-reactive pathologies. Am J Trop Med Hyg 1999; 60: 193-198.

43. Biava MF, Dao A, Fortier B. Laboratory diagnosis of cystic hydatid disease. World J Surg 2001; 25: 10-14.

44. Gottstein B. An immunoassay for the detection of circulating antigens in human echinococcosis. Am J Trop Med Hyg 1984; 33: 1185-1191.

45. Salama H, Farid Abdel-Wahab M, Strickland GT. Diagnosis and treatment of hepatic hydatid cysts with the aid of echo-guided percutaneous cyst puncture. Clin Infect Dis 1995; 1: 1372-1376.

46. Mawhorter S, Temeck B, Chang R, Pass H, Nash T. Nonsurgical therapy for pulmonary hydatid cyst disease. Chest 1997; 112: 1432-1436.

47. Das DK, Bhambhani S, Pant CS. Ultrasound guided fineneedle aspiration cytology: diagnosis of hydatid disease of the abdomen and thorax. Diagn Cytopathol 1995; 12: 173176.

48. Qian ZX. Thoracic hydatid cysts: a report of 842 cases treated over a thirty-year period. Ann Thorac Surg 1988; 46: 342-346.

49. Kilani T, El Hammami S. Pulmonary hydatid and other lung parasitic infections. Curr Opin Pulm Med 2002; 8: 218223.

50. Filice C, Brunetti E. Use of PAIR in human cystic echinococcosis. Acta Trop 1997; 64: 95-107.

51. Akhan O, Ozmen MN, Dincer A, Gocmen A, Kalyoncu F. Percutaneous treatment of pulmonary hydatid cysts. Cardiovasc Intervent Radiol 1994; 17: 271-275.

52. Behrns KE, van Heerden JA. Surgical management of hepatic hydatid disease. Mayo Clin Proc 1991; 66: 11931197.

53. Dhaliwal RS, Kalkat MS. One-stage surgical procedure for bilateral lung and hydatid cysts. Ann Thorac Surg 1997; 64: 338-341.

54. Cetin G, Dogan R, Yuksel M, et al. Surgical treatment of bilateral hydatid disease of the lung via median sternotomy: experience in 60 consecutive patients. Thorac Cardiovasc Surg 1988; 36: 114-117.

55. Petrov DB, Terzinacheva PP, Djambazov VI, et al. Surgical 
treatment of bilateral hydatid disease of the lung. Eur $J$ Cardiothorac Surg 2001; 19: 918-923.

56. Ramos G, Orduna A, Garcia-Yuste M. Hydatid cyst of the lung: diagnosis and treatment. World J Surg 2001; 25: 46-57.

57. Kilani T, El Hammami S, Horchani $\mathrm{H}$, et al. Hydatid disease of the liver with thoracic involvement. World J Surg 2001; 25: $40-45$.

58. Aktan AO, Yalin R. Preoperative albendazole treatment for liver hydatid disease decreases the viability of the cyst. Eur J Gastroenterol Hepatol 1996; 8: 877-879.

59. Erzurumlu K, Hokelek M, Gonlusen L, Tas K, Amanvermez R. The effect of albendazole on the prevention of secondary hydatidosis. Hepatogastroenterology 2000; 47: 247-250.

60. Keshmiri M, Baharvahdat $\mathrm{H}$, Fattahi $\mathrm{SH}$, et al. A placebo controlled study of albendazole in the treatment of pulmonary echinococcosis. Eur Respir J 1999; 14: 503-507.

61. Anadol D, Ozcelik U, Kiper N, Gocmen A. Treatment of hydatid disease. Paediatr Drugs 2001; 3: 123-135.

62. Bartoloni C, Tricerri A, Guidi L, Gambassi G. The efficacy of chemotherapy with mebendazole in human cystic echinococcosis: long-term follow-up of 52 patients. Ann Trop Med Parasitol 1992; 86: 249-256.

63. Galanakis E, Besis S, Pappa C, Nicolopoulos P, Lapatsanis P. Treatment of complicated pulmonary echinococcosis with albendazole in childhood. Scand J Infect Dis 1997; 29: 638640.

64. Qiu J, Schantz P, Wang Q, He J, Chen X, Liu F. Ozfendazole treatment for experimental alveolar echinococcosis in mice J Pract Parasit Dis 1999; 7: 116-119.

65. Taylor DH, Morris DL. Combination chemotherapy is more effective in postspillage prophylaxis for hydatid disease than either albendazole or praziquantel alone. Br J Surg 1989; 76: 954.

66. Cobo F, Yarnoz C, Sesma B, et al. Albendazole plus praziquantel versus albendazole alone as a pre-operative treatment in intra-abdominal hydatisosis caused by Echinococcus granulosus. Trop Med Int Health 1998; 3: 462- 466.

67. Zarzosa MP, Orduna Domingo A, Gutierrez $\mathrm{P}$, et al. Evaluation of six serological tests in diagnosis and postoperative control of pulmonary hydatid disease patients. Diagn Microbiol Infect Dis 1999; 35: 255-262.

68. Craig PS. Echinococcus granulosus: immunodiagnosis and vaccination, a perspective. Parassitologia 1997; 39: 345-347.

69. Heath DD, Holcman B. Vaccination against Echinococcus in perspective. Acta Trop 1997; 67: 37-41.

70. Lightowlers MW, Lawrence SB, Gauci CG, et al. Vaccination against hydatidosis using a defined recombinant antigen Parasite Immunol 1996; 18: 457-462.

71. Rausch RL, Wilson JF, Schantz PM, McMahon BJ. Spontaneous death of Echinococcus multilocularis: cases diagnosed serologically (by Em2 ELISA) and clinical significance. Am J Trop Med Hyg 1987; 36: 576-585.

72. Sturm D, Menzel J, Gottstein B, Kern P. Interleukin-5 is the predominant cytokine produced by peripheral blood mononuclear cells in alveolar echinococcosis. Infect Immun 1995; 63: 1688-1697.

73. Gottstein B, Bettens F. Association between HLA-DR13 and susceptibility to alveolar echinococcosis. J Infect Dis 1994; 169: 1416-1417.

74. Wilson JF, Rausch RL, Wilson FR. Alveolar hydatid disease. Review of the surgical experience in 42 cases of active disease among Alaskan Eskimos. Ann Surg 1995; 221: 315-323.

75. Akinoglu A, Demiryurek H, Guzel C. Alveolar hydatid disease of the liver: a report on thirty-nine surgical cases in eastern Anatolia, Turkey. Am J Trop Med Hyg 1991; 45: 182-189.

76. Reuter S, Nussle K, Kolokythas $\mathrm{O}$, et al. Alveolar liver echinococcosis: a comparative study of three imaging techniques. Infection 2001; 29: 119-125.

77. Gottstein B. Echinococcus multilocularis infection: immunology and immunodiagnosis. Adv Parasitol 1992; 31: 321-380.

78. Gottstein B, Jacquier P, Bresson-Hadni S, Eckert J. Improved primary immunodiagnosis of alveolar echinococcosis in humans by an enzyme-linked immunosorbent assay using the Em2plus antigen. J Clin Microbiol 1993; 31: 373376.

79. Ito A, Ma L, Schantz PM, et al. Differential serodiagnosis for cystic and alveolar echinococcosis using fractions of Echinococcus granulosus cyst fluid (antigen B) and E. multilocularis protoscolex (EM18). Am J Trop Med Hyg 1999; 60: 188-192.

80. Lanier AP, Trujillo DE, Schantz PM, Wilson JF, Gottstein B, McMahon BJ. Comparison of serologic tests for the diagnosis and follow-up of alveolar hydatid disease. $\mathrm{Am} \mathrm{J}$ Trop Med Hyg 1987; 37: 609-615.

81. Gottstein B, Mowatt MR. Sequencing and characterization of an Echinococcus multilocularis DNA probe and its use in the polymerase chain reaction. Mol Biochem Parasitol 1991; 44: 183-193.

82. Reuter S, Seitz HM, Kern P, Junghanss T. Extrahepatic alveolar echinococcosis without liver involvement: a rare manifestation. Infection 2000; 28: 187-192.

83. Kern P, Frosch P, Helbig M, et al. Diagnosis of Echinococcus multilocularis infection by reverse-transcription polymerase chain reaction. Gastroenterology 1995; 109: 596-600.

84. Reuter S, Schirrmeister H, Kratzer W, Dreweck C, Reske SN, Kern P. Pericystic metabolic activity in alveolar echinococcosis: assessment and follow-up by positron emission tomography. Clin Infect Dis 1999; 29: 1157-1163.

85. Anon. Guidelines for treatment of cystic and alveolar echinococcosis in humans. WHO Informal Working Group on Echinococcosis. Bull World Health Organ 1996; 74: 231242.

86. Ammann RW, Hirsbrunner R, Cotting J, Steiger U, Jacquier P, Eckert J. Recurrence rate after discontinuation of long-term mebendazole therapy in alveolar echinococcosis (preliminary results). Am J Trop Med Hyg 1990; 43: 506-515.

87. Wilson JF, Rausch RL, McMahon BJ, Schantz PM Parasiticidal effect of chemotherapy in alveolar hydatid disease: review of experience with mebendazole and albendazole in Alaskan Eskimos. Clin Infect Dis 1992; 15: 234 249.

88. Bresson-Hadni S, Koch S, Beurton I, et al. Primary disease recurrence after liver transplantation for alveolar echinococcosis: long-term evaluation in 15 patients. Hepatology 1999; 30: $857-864$

89. D'Alessandro A. Polycystic echinococcosis in tropical America: Echinococcus vogeli and E. oligarthrus. Acta Trop 1997; 67: 43-65.

90. Lopera RD, Melendez RD, Fernandez I, Sirit J, Perera MP. Orbital hydatid cyst of Echinococcus oligarthrus in a human in Venezuela. J Parasitol 1989; 75: 467-470.

91. D'Alessandro A, Ramirez LE, Chapadeiro E, Lopez ER, de Mesquita PM. Second recorded case of human infection by Echinococcus oligarthrus. Am J Trop Med Hyg 1995; 52: 29-33. 